\title{
Produção de animacões computadorizadas em flash para o ensino básico de Geociências
}

\author{
Production OF Flash COMPUterized animations For basic geOSCIENCE TeACHING \\ Toscani R. ${ }^{1,2}$., França G.S. ${ }^{1,3}$, Rezende E.S. ${ }^{1,4}$, Matos, D.R. ${ }^{1,5}$ \\ 1- Univ. Brasília, Inst. Geociências, Campus Univ. Darcy Ribeiro, Asa Norte, 70910-900 Brasília, DF. \\ 2- toscanisilveira@gmail.com \\ 3- georgesand@unb.br \\ 4- eduardosrezende@gmail.com \\ 5-deb.rmatos@gmail.com
}

ABSTRACT: The production of images, videos or didactic animations with the objective of teaching and disseminating Geoscience knowledge to the public is insignificant in Brazil, compared to more developed countries. Due to the lack of educational teaching elements, this project was developed to produce and provide a quality, didactic and interactive material about Geoscience and Seismology for teachers from elementary to undergraduate levels. The construction of the animations was accomplished using the Adobe Flash $\AA$ 9.0 r45 program, which allows construction of vector images with movement. Finally, this didactic material has already been presented with broad approval to an audience of over 500 people in many places, such as universities, public schools and extension weeks. Besides, it was realized an online research, divulgated by the page of the Seismologic Observatory of University of Brasilia on social networks, with 316 participants. The coefficient of approval by the participants was $85.2 \%$. The respondents specially enjoyed the themes, the didactic and quality of the animations.

\section{Manuscrito: \\ Recebido: 23/05/2017 \\ Corrigido: 30/08/2017 \\ Aceito: 14/11/2017}

Citation: Toscani R., França G.S., Rezende E.S., Matos, D.R. 2017. Produção de animações computadorizadas em flash para 0 ensino básico de Geociências. Terræ Didatica, 13(3):271-278. <http://www.ige. unicamp.br/terraedidatica/>

Keywords: Geosciences teaching, Seismology, animations, computers.

\section{Introdução e Objetivos}

O Brasil apresenta carência significativa na produção de conteúdos de ensino didático, especialmente voltados para a área de Geociências, se comparado a países da Europa e aos Estados Unidos (Bourotte et al. 2014). São raras as vezes que se veem vídeos, animações ou maquetes fabricadas em território nacional. Além disso, trabalhos recentes indicam contínua diminuição no interesse dos estudantes diante dos estudos científicos (Fourez 2003, Imbernon et al. 2009).

$\mathrm{O}$ uso de animações computadorizadas pode potencializar o ensino de Geociências, por meio da representação de conceitos, fenômenos e processos, muitas vezes impossíveis de vivenciar. Além disso, as animações que podem integrar recursos de imagem, texto e áudio têm se configurado como importantes recursos educativos devido a sua capacidade de demonstrar processos; apoiar a visualização de determinados eventos; expor fenômenos raros, complexos ou perigosos, e pela possibilidade de simularem determinados modelos ou sistemas (Medeiros \& Medeiros 2002, Mendes 2011, Magarão 2013).

Em experimento realizado com estudantes universitários de Ilinois, Estados Unidos, notou-se que o ensino de Geociências por meio de tecnologias de informática, tais como apresentações de slides, figuras e animações, melhorou consideravelmente o rendimento discente. As turmas que tinham acesso a este conteúdo apresentaram notas $23 \%$ maiores em relação a turmas que usavam apenas formas tradicionais de ensino, o que provocou o efeito de um maior índice de aprovação de $86 \%$, enquanto que nas classes ausentes de recursos de informática o percentual foi de apenas $57 \%$. Finalmente, 80 a $86 \%$ dos estudantes que tiveram acesso às tecnologias de aprendizagem consideraram-nas um recurso didático útil (Durbin 2002). 
Um exemplo moderno de programa educacional é o EPO (The Incorporated Research Institutions for Seismology's Education and Public Outreach), desenvolvido por pesquisadores da IRIS (Incorporated Research Institutions for Seismology), que tem como objetivo promover a conscientização e a compreensão da Geofísica e da Sismologia entre o público geral e ao mesmo tempo inspirar a formação de futuras carreiras na área das ciências da Terra (Taber et al. 2015). Parte do material disponibilizado pelo EPO são animações que explicam conceitos sismológicos e histórias sobre pesquisas recentes. Outro projeto igualmente dinâmico é o Seischool Norway, voltado para despertar o interesse e divulgar informações sobre Sismologia e Geociências entre estudantes de ensino médio da Noruega (Boulaenko e Husebye 2003). Parte do projeto consiste em uma plataforma da internet que promove o ensino por meio de ferramentas interativas, sendo as animações computadorizadas um dos principais recursos.

O uso de material multimídia possibilita que o conteúdo seja passado de maneira mais dinâmica, sem a necessidade de produzir longos textos e ao mesmo tempo permite trabalhar com situações-problema de maior complexidade com os alunos. Farley (2016) mostra que apesar de o uso de animações ser comum em apresentações orais em eventos científicos, o mesmo não ocorre em artigos escritos. Segundo o mesmo pesquisador, o uso de animações permite ao espectador ou leitor que examine ou mesmo avalie a interpretação de um autor de maneira muito mais rápida e intuitiva que em imagem fixas. Atualmente, a maior parte dos leitores acessa a versão digital, e não impressa de periódicos, por conta disso seria conveniente e prático que se passasse a ser mais comum o uso animações nas versões digitais de artigos.

No Brasil, Carli (2016) obteve resultados satisfatórios ao fazer o uso de animações como material didático para o ensino de Geofísica. Segundo este autor, as animações oportunizam visualização ampla e rápida e possibilitam assimilação mais amigável e intuitiva do conteúdo. O ensino de modelos e aplicações geofísicas geralmente exige do interlocutor o conhecimento prévio de equações e variáveis, a maioria das vezes desconhecidas pelo usuário comum, o que pode provocar a perda do interesse a um maior aprofundamento desta ciência por parte das pessoas. Desta maneira, o uso das animações como forma de representar modelos geofísicos acaba por ser ferramenta mais simples e didática, tanto para pesquisadores e profissionais do ramo, quanto para o público leigo.

A utilização de animações no formato flash como elemento motivador de aprendizagem já foi empregada com sucesso entre estudantes brasileiros do ensino médio na explicação fenômenos físicos. Constatou-se também a importância de disponibilizar publicamente as animações na internet de maneira que o usuário pudesse repeti-las quantas vezes fossem necessárias segundo o seu próprio ritmo de aprendizado (Castilho et al. 2006).

Este trabalho pretende contribuir com a propagação do ensino das Geociências, podendo ser usado por professores desde o ensino fundamental até a graduação, mais especificamente na parte de Geociências voltada para a Sismologia, por meio da construção de animações computadorizadas que abrangem tópicos da Geologia e Geofísica, áreas de estudo em geral pouco divulgadas na mídia e por isso menos acessíveis ao público comum.

\section{Método de Ensino com Utilização de Animações Computadorizadas}

A construção das animações foi realizada pelo programa Adobe Flash ${ }^{\circledR} 9.0$ r45 (disponível em łttps://get.adobe.com/br/flashplayer), o qual permite a construção de imagens vetoriais com movimento. A realização desse material foi feita em conjunto por professores e alunos do Instituto de Geociências da Universidade de Brasília e tiveram como embasamento teórico os livros didáticos introdutórios voltados para Geociências básica como o "Decifrando a Terra" de Teixeira et al. (2001) e o "Para Entender a Terra" de Press et al. (2008).

Os produtos obtidos foram separados em seis etapas de ensino às quais seguem uma ordem que facilita o aprendizado dos estudantes. Realizaram-se ao todo dezesseis animações e ilustrações vetoriais. Para visualizar as animações é necessário utilizar os navegadores Internet Explorer ${ }^{\circledR}$ ou Microsoft Edge $\AA$. As animações também fazem parte da Mostra Sismológica do Observatório Sismológico da Universidade de Brasília e são usadas de suporte na explicação de maquetes didáticas e demais objetos do local (Toscani et al. 2012).

\section{Etapa 1 - Explicação sobre as origens dos terremotos}

Nesta etapa, procurou-se explanar a origem dos terremotos, relacionando-os às falhas geológicas, às atividades vulcânicas ou à sismicidade induzida. 
Além disso, como se pode visualizar (Fig. 1) há uma breve explicação sobre os termos epicentro, hipocentro e apresenta uma relação entre a movimentação das placas e a propagação das ondas sísmicas. A animação é essencial para o entendimento da relação entre as falhas geológicas e a origem dos abalos sísmicos, sendo usada também para o entendimento da teoria do Rebote Elástico. Segundo esta teoria, um tremor de terra ocorre quando a força elástica em algum ponto da falha supera a força de atrito, provocando assim um deslizamento abrupto (Press et al. 2008).

\section{Etapa 2 - Características básicas das ondas sísmicas (P, S, Rayleigh e Love)}

Neste estágio, realizaram-se quatro animações que mostram as características das ondas sísmicas de corpo e superficiais (Fig. 2). Esta figura e o texto explicativo estão embasados nos livros de Teixeira et al. (2001) e de Press et al. (2008):

- Ondas P: Apresentam maior velocidade (4 a $8 \mathrm{~km} / \mathrm{s}$ ), propagam-se em todos os meios com vibração da partícula paralela a direção de propagação. Correspondem a sucessivas compressões e dilatações nos meios de propagação.

- Ondas S: Propagam-se somente em corpos sólidos com velocidade cerca de $60 \%$ menor que da onda P. As vibrações seguem movimentos cisalhantes perpendiculares à direção de propagação da onda.

- Ondas Love: Apresentam cisalhamento horizontal sendo resultado da interferência de duas ondas $\mathrm{S}$.

- Ondas Rayleigh: Formadas pela interferência

das ondas $\mathrm{Pe} \mathrm{S}$, originando órbita elíptica. A amplitude diminui rapidamente com a profundidade e possuem velocidade ligeiramente mais lenta que das ondas Love.

Esta etapa exemplifica a importância das animações. Uma vez que o texto explicativo mesmo sendo sucinto e preciso, exige o conhecimento prévio de termos mais sofisticados utilizados pela comunidade científica como "cisalhantes", "órbita elíp-

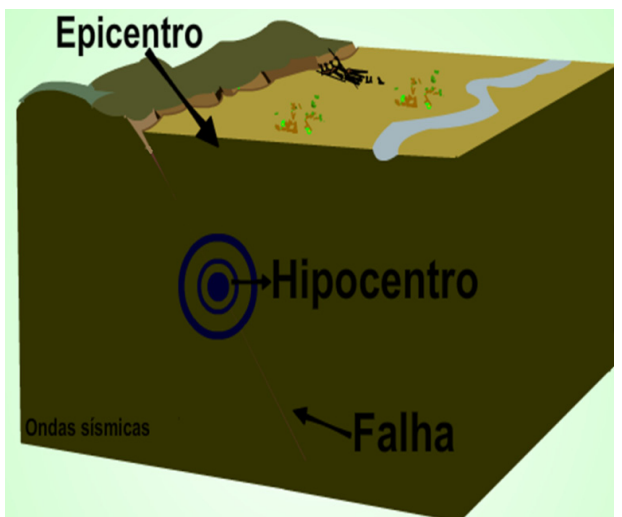

Figura 1. Imagem da animação tridimensional que relaciona os termos epicentro, hipocentro e propagação das ondas sísmicas mediante a movimentação das falhas geológicas.

tica", "perpendiculares" e "amplitude". O entendimento das características dos movimentos das ondas sísmicas torna-se mais simples e intuitivo pelo uso das animações e possibilita atingir pessoas com níveis mais variados de escolaridade.

\section{Etapa 3 - Mapa de movimentação tectônica e camadas do interior da Terra.}

Nesta parte da explanação, mostrou-se com um mapa animado onde estão localizadas as principais placas tectônicas e seus respectivos movimentos. Vale lembrar que nas zonas de contato, os esforços de deformação crescem, ocorrendo periodicamente sismos.

Houve ainda uma síntese das principais camadas da terra divididas tanto a nível geodinâmico o qual enfatiza o aspecto reológico das rochas (litosfera, astenosfera, mesosfera, endosfera) quanto a nível geoquímico o qual é composto pela crosta, manto superior, manto inferior, núcleo externo e

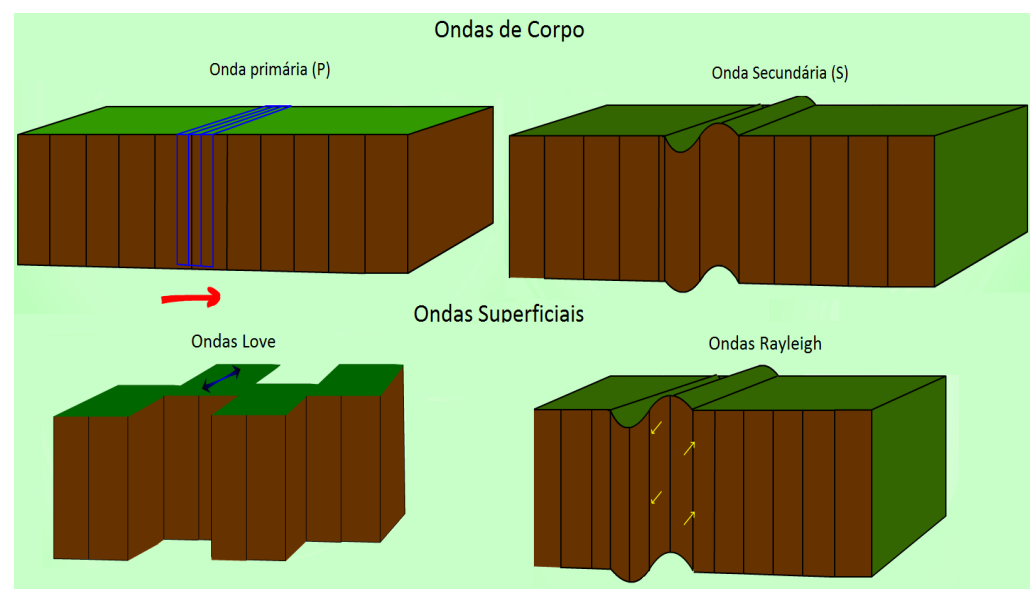

Figura 2. Imagem da animação com as principais características das ondas sísmicas mais significativas ( $P, S$, Rayleigh e Love). 

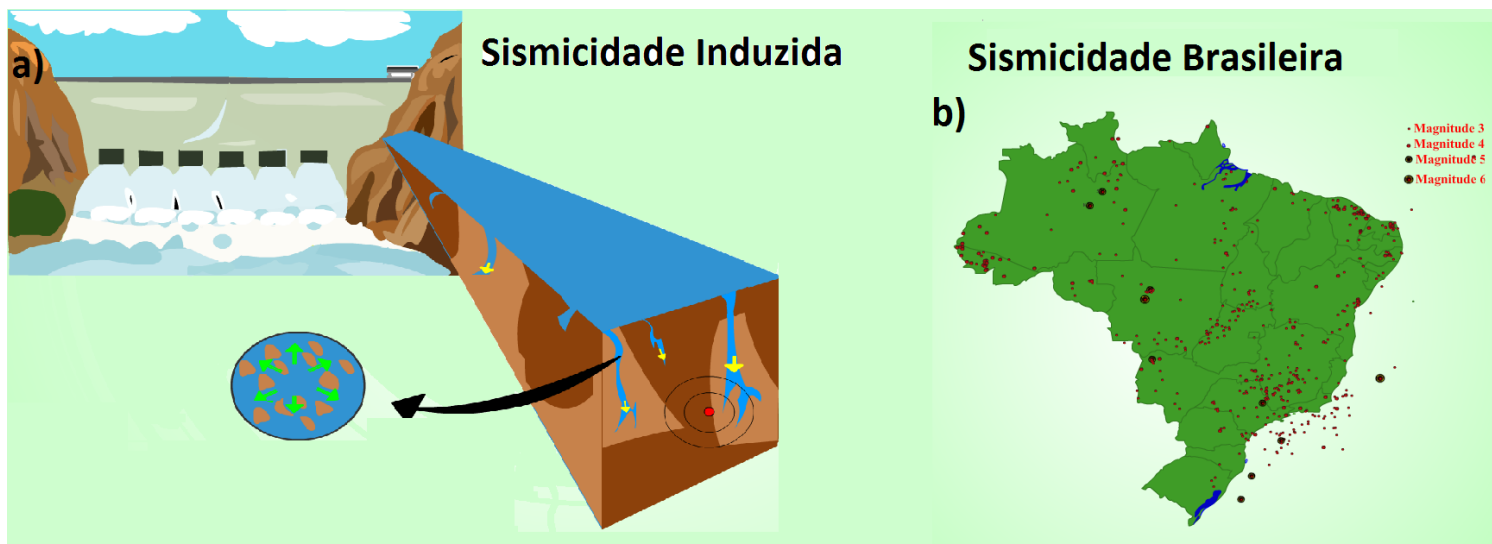

Figura 3. a) Pressão hidrostática exercida por uma barragem, podendo gerar sismicidade induzida. b) Principais sismos ocorridos no Brasil, desde 1970 a 2010.

núcleo interno. Vale ressaltar que o aspecto geodinâmico é o mais apropriado quando se pretende compreender a movimentação das placas tectônicas.

\section{Etapa 4 - Correntes convectivas e ambientes tectônicos}

Em um primeiro momento, faz-se notar a importância dos efeitos convectivos para a movimentação das placas tectônicas. Posteriormente visualizam-se animações dos principais ambientes tectônicos, enfatizando as características fundamentais dos ambientes convergentes, divergentes e transformantes .

As animações demonstram de maneira clara a relação do movimento das correntes de convecção com a direção e o sentido do movimento relativo das placas tectônicas acima destas.

Vale salientar, que outro mecanismo importante para a movimentação das placas é a diferença de densidade entre as porções mais jovens das placas que são mais quentes e menos densas e se encontram geralmente em limites divergentes e as porções mais antigas que são frias e densas e sofrem frequentemente subducção por ação do efeito gravitacional.

\section{Etapa 5 - Deriva continental}

Aborda a origem e o histórico da teoria da deriva continental, com imagens vetoriais de fósseis que comprovam essa hipótese, bem como uma série de imagens que evidenciam a evolução da Terra desde o Permiano até o Quaternário .

Uma animação mostra, por exemplo, como a população de Cynognathus se distribuía durante o Triássico compreendendo uma área correspondente onde hoje é a África e América do Sul. A animação prossegue com a tafrogênese do Pangeia até o posi- cionamento atual dos continentes, demonstrando assim ao usuário, de maneira clara, o motivo de este fóssil poder ser encontrado em locais tão distantes.

\section{Etapa 6 - Magnitude, Sismicidade induzida e sismicidade no Brasil}

Enfoca princípios de magnitude, sismicidade, bem como os principais sismos ocorridos no Brasil, desde 1970 a 2010 (Fig. 3b).

Nesta etapa são explicadas as características da magnitude, a qual é uma medida quantitativa do tamanho do terremoto, relacionando a energia sísmica liberada no foco e a amplitude das ondas registradas. A escala é logarítmica, deste modo, um acréscimo de um grau na magnitude aumenta 10 vezes a amplitude de uma onda e de 32 vezes a energia liberada.

Além disso, são abordados tópicos da sismicidade induzida: como a construção de barragens aumenta a pressão hidrostática, podendo antecipar ou amplificar a magnitude de um sismo (Fig. 3a).

\section{Resultados}

Após a finalização das animações, realizou-se uma pesquisa via internet a fim de avaliar as animações de forma quantitativa. A pesquisa era constituída por seis perguntas referentes às animações descritas neste artigo e ficou disponível na página do perfil da Mostra Sismológica em uma rede social e continha um link de acesso às animações. O questionário foi respondido de forma anônima por 316 voluntários e serão apresentados a seguir.

Iniciou-se o questionário com a seguinte indagação: "Você poderia avaliar as animações em Geociências em uma escala de 0 a 4 , sendo 4 muito bom e 0 péssimo?". Os dados mostraram que 85,2\% 
Você poderia avaliar as animações em Geociências em uma escala de 0 a 4 , sendo 4 muito bom e 0 péssimo?



Figura 4. Gráfico com o porcentual das respostas dos voluntários à primeira pergunta do questionário: "Você poderia avaliar as animações em Geociências em uma escala de 0 a 4 , sendo 4 muito bom e 0 péssimo?"

das pessoas responderam entre " 3 " e " 4 ", enquanto que $12 \%$ responderam " 2 " e $2,8 \%$ dos participantes responderam "1". Nenhum voluntário avaliou as animações em "0" ou péssimo (Fig. 4). Este questionamento permitiu avaliar a qualidade das animações, que foram aprovadas pela grande maioria dos participantes.

A segunda pergunta foi: "Você considera que o uso de animações em sala de aula, como as que foram mostradas, auxiliam no aprendizado dos estudantes?". Entre as pessoas que responderam o questionário (Fig. 5), 94,9\% responderam que "Sim", enquanto que 4,5\% responderam "Talvez" e $0,6 \%$ disseram que não sabiam opinar. Nenhum dos voluntários respondeu "Não". Assim, foi possível avaliar o uso das animações como uma importante ferramenta didática.

Você considera que o uso de animações em sala de aula, como as que foram mostradas, auxiliam no aprendizado dos estudantes?

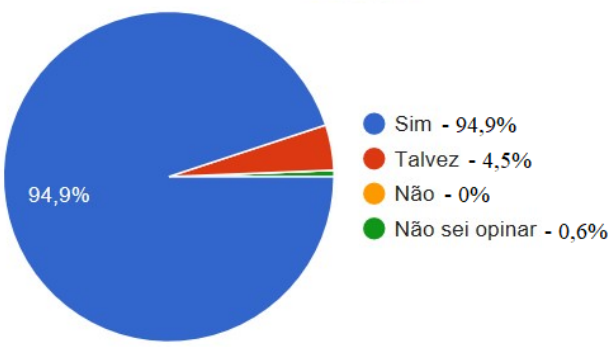

Figura 5. Gráfico com a porcentagem das respostas dos voluntários à segunda pergunta do questionário: "Você considera que o uso de animações em sala de aula, como as que foram mostradas, auxiliam no aprendizado dos estudantes?"

O terceiro questionamento foi "Você acredita que essas animações poderão, em um futuro próximo, serem implementadas por professores de todo o país?”. O resultado (Fig. 6) foi que $74,7 \%$ dos voluntários responderam "Sim", 21,5\% responderam "Talvez", 1,9\% responderam "Não" e outros $1,9 \%$ não souberam opinar. Esta pergunta avalia em conjunto a didática, a praticidade e mais uma vez a qualidade dessas animações. É importante também para verificar a possibilidade da ampla divulgação do material especialmente no nível fundamental e médio.

Você acredita que essas animações poderão, em um futuro próximo, serem implementadas por professores de todo o país?

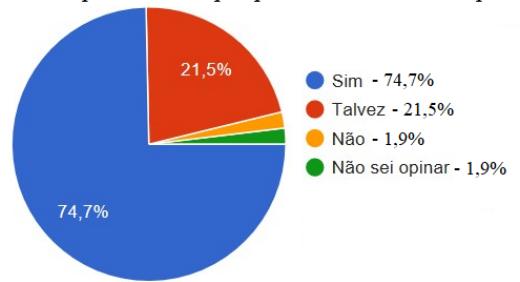

Figura 6. Gráfico com a porcentagem das respostas dos voluntários a terceira pergunta: "Você acredita que essas animações poderão, em um futuro próximo, serem implementadas por professores de todo o país?"

A quarta pergunta do questionário foi: "O que mais te chamou a atenção nas animações?" (Fig. 7). Nesta fase do questionário $37,3 \%$ dos voluntários consideraram que era o tema, por este ser pouco conhecido pela população em geral. Já $29,7 \%$ responderam que foi a forma como o tema foi abordado. Para 16,8\% julgaram que foi o próprio conteúdo, por este ser relevante a sismologia. Finalmente, 16,2\% julgaram que era a qualidade das animações, por conta das cores e movimentos. Objetivou-se com o questionamento revelar qual característica das animações mais se destacava, nesse caso, a resposta foi a própria temática delas.

$\mathrm{O}$ que mais te chamou a atenção nas animações?



Figura 7. Gráfico com a porcentagem das respostas dos voluntários à quarta pergunta: "O que mais te chamou a atenção nas animações?".

O quinto questionamento era: "Antes de ter acesso às animações, qual era o seu grau de conhecimento de Sismologia?" (Fig. 8). Segundo 44\% dos voluntários o grau de conhecimento em Sismologia era baixo. Para $29,5 \%$ o seu grau de conhecimento era intermediário, enquanto que $18 \%$ responderam 
que o grau era alto e $8,5 \%$ consideraram que era inexistente.

Por conta de o questionário estar disponível numa página da internet relacionada à Mostra Sismológica, é possível que muitos dos que responderam à pesquisa fossem alunos ou ex-alunos do Instituto de Geociências da UnB, ou até mesmo pessoas que ocasionalmente já visitaram a Mostra, pois uma porção considerável, ou seja, $47,4 \%$ dos entrevistados, disseram ter um grau intermediário ou alto de conhecimento em relação à Sismologia. Este fator é importante, pois essas pessoas provavelmente puderam fazer uma avaliação mais precisa em relação às animações. Mesmo assim, a maior parte do público apresenta baixo ou nenhum conhecimento na área (52,6\%), evidenciando a importância da divulgação desse conteúdo para o público leigo.

Antes de ter acesso às animações, qual era o seu grau de conhecimento de sismologia?

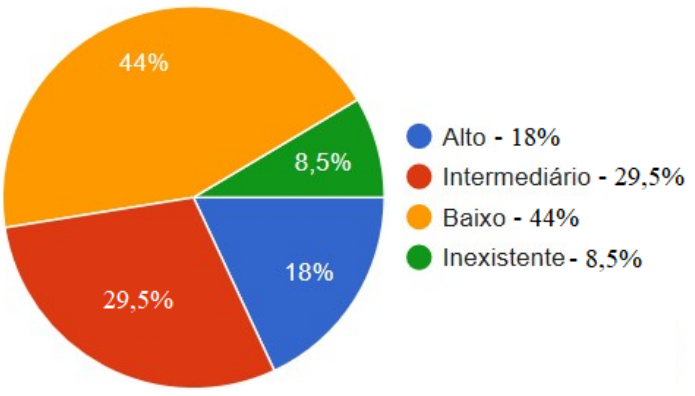

Figura 8. Gráfico com a porcentagem das respostas dos voluntários à quinta pergunta: "Antes de ter acesso às animações, qual era o seu grau de conhecimento de Sismologia?"

Em relação a sexta e última pergunta do questionário (Fig. 9): "Após a visualização das animações, você acredita ter melhorado seu conhecimento em Geociências?", 85,8\% dos voluntários responderam que sim enquanto que $14,2 \%$ responderam "não". Esta última pergunta revela que mesmo entre os participantes que consideraram ter um médio a alto conhecimento em Sismologia $(47,4 \%)$, as animações ainda puderam acrescentar algum conteúdo ou informação nova.

Do ponto de vista qualitativo é bastante perceptível como as animações computadorizadas facilitam muito a transmissão dos conhecimentos das Geociências, tornando-os mais simples e intuitivos.

As animações já eram empregadas em 2011, momento em que houve uma procura maior do público pela Mostra Sismológica. Este fenôme- no foi decorrente principalmente do Tsunami ocorrido no mesmo ano no Japão, algo já descrito como "momentos ensináveis" por Schwarz (2004). Segundo este autor, sempre que ocorre algum terremoto de grande repercussão, é comum que se desperte uma curiosidade maior das pessoas pela Sismologia. Dessa forma, as animações foram bastante oportunas para que se pudesse cativar os novos visitantes e espectadores da Mostra Sismológica.

As animações foram expostas constantemente aos visitantes da Mostra Sismológica do Observatório Sismológico, tendo contribuído para boas apresentações. Nota-se, principalmente nas visitas do Ensino Fundamental, que os desenhos tornam mais atraentes os assuntos abordados, prendendo a atenção e despertando curiosidade pelas Geociências. As animações tornaram o público mais envolvido durante as visitações à Mostra Sismológica, inclusive estimulando as pessoas a fazerem perguntas. Uma prova são os frequentes elogios vindos de professores; muitos deles levam outras turmas nos anos seguintes, outros ainda convidam os colaboradores e bolsistas da Mostra Sismológica a se deslocarem e realizarem palestras nas próprias escolas.

A Mostra Sismológica também participou durante vários anos da Semana Nacional de Ciência e Tecnologia, ocasião em que foram feitas apresentações envolvendo animações computadorizadas. Nestes eventos o estande da Mostra Sismológica foi indiscutivelmente um dos ambientes mais frequentados pelo público, com elogios quanto à forma didática como os conteúdos foram apresentados. O mesmo pode-se dizer sobre a atuação da Mostra durante o $12^{\circ}$ Congresso Internacional da Sociedade Brasileira de Geofísica no Rio de Janeiro, pois as apresentações agradaram pesquisadores de

Após a visualização das animações, você acredita ter melhorado seu conhecimento em Geociências?

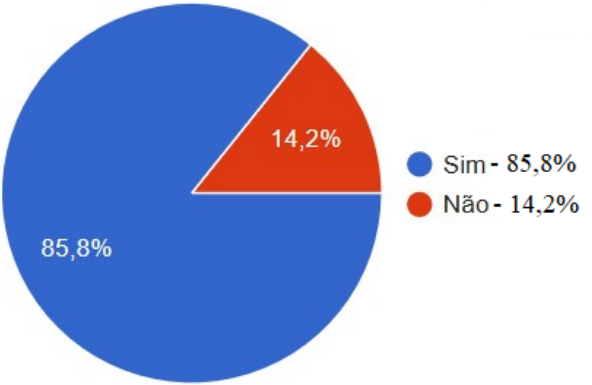

Figura 9. Gráfico com a porcentagem das respostas dos voluntários à sexta pergunta: "Após a visualização das animações, você acredita ter melhorado seu conhecimento em Geociências?". 
outras universidades e até mesmo de outros países.

Atualmente, a Mostra Sismológica é reconhecida como um ambiente formal de divulgação de ciência e faz parte inclusive do Guia de Turismo Científico de Brasília (Secretaria de Ciência, Tecnologia e Inovação e Secretaria de Turismo de Brasília. 2016), desenvolvido pelo Governo do Distrito Federal, a fim de beneficiar alunos e professores da Rede Pública de Ensino do Distrito Federal, turistas e a população em geral. Está presente também no Guia de Museus Brasileiros (Instituto Brasileiro de Museus. 2011), publicação relacionada ao Ministério da Cultura a fim de facilitar o acesso do público aos acervos brasileiros e difundir informações do setor museal no país.

\section{Conclusões}

O ensino de Geociências inclui disciplinas cujos conhecimentos e conceitos são de difícil compreensão e assimilação, tendo em vista seu elevado nível de abstração e formas complexas de representação. Com isso, a realização de animações computadorizadas como as exemplificadas neste artigo são de fundamental importância para a divulgação da ciência tanto para um público leigo quanto para estudantes de graduação.

O uso da tecnologia contribuiu também para acrescentar qualidade e didática às apresentações da Mostra Sismológica do Observatório Sismológico de Brasília. As animações são importantes para envolver o visitante, de maneira que ele possa compreender melhor as maquetes expostas no local e despertar maior interesse e curiosidade pelas Geociências. Finalmente, as ferramentas de aprendizagem servem para ilustrar a alunos e professores do ensino médio e fundamental que o aprendizado pode ser algo lúdico e dinâmico.

Por fim, vale salientar que esse material didático já foi explanado para um público superior a 500 pessoas em diversos locais como na Mostra Sismológica, em escolas públicas e em semanas nacionais de ciência e tecnologia com ampla aprovação, principalmente, pelo público discente e docente. Além disso, o resultado da pesquisa envolvendo 316 pessoas evidenciou a aprovação dos participantes de $85,2 \%$, especialmente devido à temática, didática e qualidade das animações.

\section{Referências}

Boulaenko M.E., Husebye E.S. 2003. Electronic learning modules for high school students in seismology. Seismol. Res. Letters, 74(5):580-587.

Bourotte C.L.M., Toledo M.C.M., Duleba W., Aramaqui G.T., Campos L.G.D., Viana P.J. 2014. Kit didático da rocha ao grão... de areia. Terrae Didatica, 10(3):298-304.

Carli J.C.A., Fries M., Gonçalves L.R.S. 2016. A geofísica aplicada à engenharia e estudos ambientais: uso de animações como recurso didático. In: Salão Interno Ens. Pesq. e Extensão, 7, Uruguaiana, RS 22-24 nov 2016 Anais...(1). Uruguaiana: Unipampa. p. 1.

Castilho M.I., Ricci T.D.S.F. 2006. O uso de animações como elemento motivador de Aprendizagem. In: Enc. Est. Ens. Física, 1, Porto Alegre, RS, 24-26 nov 2005. Atas... Porto Alegre: Inst. Física/UFRGS. p. $108-114$.

Durbin J. M. 2002. The benefits of combining computer technology and traditional teaching methods in large enrollment geoscience classes. J. Geosc. Educ., 50(1):56-63.

Fourez G. 2016. Crise no ensino de ciências? Invest. Ens. Ciências, 8(2):109-123.

Imbernon R.A.L., Toledo M.C.M., Honório K.M., Tufaile A.P.B., Vargas R.R.S., Campana P.T., Falconi S., Malachias M.E.I 2014. Experimentação e interatividade (hands-on) no ensino de ciências: a prática na praxis pedagógica. Terre Didatica, 10(3):298-304.

Instituto Brasileiro de Museus. Guia dos Museus Brasileiros. Brasília (DF), URL: http://www.museus.gov. br/guia-dos-museus-brasileiros/ Acesso: 02/11/2016

Magarão J.F.L Giannella T., Struchiner M., 2013. Uso de Animações sobre Saúde no Ensino das Ciências Naturais: Levantamento e Análise de Recursos Disponíveis no Portal do Professor (MEC). In: Enc. Nac. Pes. Edu. Ciências, 9, Águas de Lindóia, SP, 10-13 nov 2013. Atas... Águas de Lindóia: Majestic, Bela Vista p. 1-8.

Marfurt K. J., Farley I. 2016. Let's get animated! Interpretation, $4(2): 1 \mathrm{M}-5 \mathrm{M}$

Medeiros A., Medeiros C.F. 2002. Possibilidades e limitações das simulações computacionais no ensino da Física. Rev. Bras. Ens. Física. 24(2):77-86.

Mendes, M. 2011. Produção e utilização de animações e vídeos no ensino de biologia celular para a primeira série do ensino médio. Brasília: Inst. Ciênc. Biol, 103p. (Dissert. Mestrado).

Press F., Siever R., Grotzinger J., Jordan T. H. 2006. Para entender a Terra. $4^{\mathrm{a}}$ ed. Porto Alegre: Bookman. 656p.

Schwarz, S. (2004). Cyberseismology and teachable moments. Seismological Research Letters, 75(6):749-750.

Secretaria de Estado de Ciência, Tecnologia e Inovação \& Secretaria de Turismo de Brasília. 2016. Guia Turístico Científico de Brasília. Brasília, (DF). URL: http://www. brasilia.df.gov.br/wp-conteudo/uploads/2016/07/ GUIA-FINAL-1.pdf. Acesso 18/04/2017.

Taber J.J., Bravo T.K., Dorr P.M., Hubenthal M., Johnson J.A., McQuillan P., [...], Welti R. 2015. Promo- 
ting seismology education and research via the IRIS Education and Public Outreach Program. In: $A G U$ Fall Meeting Abstracts San Francisco, EUA.

Teixeira W., Toledo M.C.M., Fairchild T.R., Taioli F. 2001. Decifrando a Terra. São Paulo: Oficina de Textos. 624p.
Toscani R.G, França G.S, Rezende E.S, Nizio T.F.S. 2012. Ensino dinâmico de sismologia por meio de maquetes. In: Congr. Bras. Geol. 46, Santos, SP, 30 set -6 out 2012. Anais... Santos: SBG. URL: http://www.sbgeo.org.br/home/pages/44 Acesso 16/11/20017.

Resumo: No Brasil, a produção de imagens, vídeos ou animações didáticas com a finalidade de popularizar e ensinar o conhecimento de Geociências para o público leigo é ínfimo se comparado a países mais desenvolvidos. Devido a essa carência de elementos de ensino foi desenvolvido este projeto que visa produzir e proporcionar um material de qualidade, didático e interativo, para professores desde 0 ensino fundamental até a graduação, mais especificamente na parte de Geociências voltada para a Sismologia. A construção das animações foi realizada pelo programa Adobe Flash ${ }^{\circledR} 9.0$ r 450 qual permite a construção de imagens vetoriais com movimento. Vale salientar que o material didático já foi explanado para um público superior a 500 pessoas em diversos locais como em universidades e escolas públicas com ampla aprovação. Além disso, foi realizada pesquisa na internet, divulgada pelo perfil do Observatório Sismológico da Universidade de Brasília em redes sociais, contando com a participação de 316 pessoas, em que se evidenciou a aprovação dos participantes em 85,2\%, quanto à temática, didática e qualidade das animações.

Palavras-Chave: Ensino de Geociências, Sismologia, animações, computadores. 